Published in final edited form as:

Front Horm Res. 2013 ; 41: 1-15. doi:10.1159/000345666.

\title{
Multiple Endocrine Neoplasia Type 1
}

\author{
Sunita K. Agarwal \\ Metabolic Diseases Branch, National Institute of Diabetes and Digestive and Kidney Diseases, \\ $\mathrm{NIH}$, Bethesda, Md., USA
}

\section{Abstract}

Multiple endocrine neoplasia type 1 (MEN1) is an autosomal-dominant tumor syndrome characterized by the occurrence of tumors in multiple endocrine tissues and nonendocrine tissues. The three main endocrine tissues most frequently affected by tumors are parathyroid (95\%), enteropancreatic neuroendocrine (50\%) and anterior pituitary (40\%). Tumors are caused by a heterozygous germ-line-inactivating mutation in the $M E N 1$ gene (1st hit) followed by somatic inactivating mutation or loss of the normal copy of the gene (2nd hit), leading to complete loss of function of the encoded protein menin. Most of the disease features and tumors are recapitulated in mouse models with heterozygous germline loss of the Men1 gene. Also, tissue-specific tumors are observed in mouse models with homozygous somatic loss of the Men1 gene specifically in MEN1-associated endocrine tissues. Hence, mouse models could serve as possible surrogates for studying MEN1 and related states. To gain insights into MEN1 pathophysiology, menininteracting partners and pathways have been identified to investigate its tumor suppressor and other functions. Also, the 3D crystal structure of menin has been deciphered which could be useful to reveal the relevance of MEN1 gene mutations and menin's interactions. This chapter covers clinical, genetic and basic findings about the MEN1 syndrome, MEN1 gene and its product protein menin.

Multiple endocrine neoplasia type 1 (MEN1) is an autosomal-dominant tumor syndrome with no gender bias and with an approximate prevalence of 1 in 30,000 individuals. The disease, first described in two families in 1954, manifests as multiple hormone-secreting tumors, hormone nonsecreting tumors and nonendocrine tumors [1-3]. The disease manifests in adults around 40-50 years of age; however, early onset of the disease has been observed in a few children before the age 10 years [3]. Germline heterozygous mutation in the MEN1 tumor suppressor gene encoding menin, located on chromosome 11q13, predisposes to the development of tumors. This chapter covers the clinical, genetic and basic findings about the MEN1 syndrome, MEN1 gene and its protein product menin.

\section{Clinical Characteristics of MEN1}

MEN1 is characterized by the occurrence of tumors in multiple endocrine tissues and in nonendocrine tissues (table 1). The three main endocrine tissues most frequently affected by tumors in MEN1 are parathyroid (95\%), enteropancreatic neuroendocrine (50\%) and

Sunita K. Agarwal, PhD, National Institutes of Health, NIDDK, Metabolic Diseases Branch, Bldg 10, Room 8C-101, 9000 Rockville Pike, Bethesda, MD 20892 (USA), SunitaA@mail.nih.gov. 
anterior pituitary (40\%). Typical MEN1 is defined as tumor in two of the three main endocrine tissues, which in familial MEN1, includes at least one relative with tumor in one of the three main endocrine tissues [3]. In addition, an MEN1 patient could present with many other hormone-secreting, hormone nonsecreting and nonendocrine tumors: adrenal cortical tumor, foregut carcinoid (bronchial, thymic or of the gastric enterochromaffin-like cells), facial angiofibroma, truncal collagenoma, lipoma, meningioma, Barrett's esophagus, leiomyoma (uterine in females, or in the esophagus), and ependymoma [3]. Approximately $25 \%$ of MEN1 patients die from cancer due to malignant gastrinoma (enteropancreatic neuroendocrine tumor) or foregut carcinoid tumor [3].

Primary hyperparathyroidism from parathyroid hormone-secreting multiple parathyroid adenomas is usually the first clinical manifestation observed in MEN1 patients typically between 20 and 25 years of age [3]. In a few patients, the first clinical manifestation has been observed as tumors of the enteropancreatic neuroendocrine tissues (multiple gastrinoma) or anterior pituitary (prolactinoma) [3]. Eventually the patients develop various combinations of the 20 or more tumor types associated with the MEN1 syndrome (table 1). MEN1-associated endocrine tumors are named after the hormones that these tissues produce because majority of these tumors secrete excessive amounts of hormone. Some endocrine tumors can be hormone non-secreting, therefore, clinically nonfunctioning (NF). The frequently observed skin lesions, facial angiofibroma (85\%), truncal collagenoma (70\%), and lipoma (30\%) have been considered to be helpful for presymptomatic diagnosis prior to the appearance of the hormone-secreting tumors [3]. The earliest manifestation of MEN1 has been reported in two cases of insulinoma at age 6 years, and one case with pituitary macro-adenoma secreting prolactin and growth hormone at age 5 years or earlier [3]. Hence, routine periodic monitoring for tumors in asymptomatic MEN1 at-risk individuals by biochemical tests (for substances secreted by the hormone-secreting tumors) and imaging tests has been recommended beginning in early childhood at age 5 years [3].

\section{Genetics of MEN1}

Genetic linkage studies in kindreds, and loss-of-heterozygosity (LOH) studies in tumors established linkage of the MEN1 syndrome to chromosome 11q13 in 1988 [4].

Subsequently, in 1997, the MEN1 gene was identified by a positional cloning approach [5, 6]. The 9-kb MEN1 gene contains 10 exons transcribed into a 2.8-kb mRNA which encodes a 610 amino acid protein named menin (NCBI Reference Sequence: NM_130799.2, human menin isoform-2). Screening of the coding region and splice junctions has identified a heterozygous germline mutation of the MEN1 gene in 70\% of typical MEN1 index cases (familial or sporadic). No germline promoter mutations have been reported, and large deletions have been reported as rare in the MEN1 gene [7]. Germline-inactivating mutation (1st hit) predisposes to the development of tumors in adults; tumors arise after loss of the remaining normal copy of the MEN1 gene (2nd hit), classifying the $M E N 1$ gene as a tumor suppressor gene. More than $95 \%$ of tumors from MEN1 patients show LOH at chromosome $11 \mathrm{q} 13$ [7].

MEN1 gene mutation analysis has helped to identify the cause of various sporadically occurring tumors of the same types that are observed in the MEN1 syndrome. Somatic LOH 
at chromosome 11q13 is observed in 5-50\% of such noninherited commonly occurring sporadic tumors [7]. Somatic MEN1 gene mutation analysis has revealed that a fraction of these tumor types possess inactivating mutation in the MEN1 gene: parathyroid adenoma (18\%), gastrinoma (38\%), insulinoma (14\%), VIPoma (57\%), nonfunctioning pancreatic tumor (16\%), glucagonoma (60\%), adrenocortical tumor (2\%), bronchial carcinoid (35\%), anterior pituitary tumor (3.5\%), angiofibroma (10\%) and lipoma (28\%) [7].

Mutations in the MEN1 gene are dispersed over the entire coding region with no significant hot spots, and no significant genotype/phenotype correlation with the tumor spectrum or with the clinical characteristics. More than 1,000 mutations have been reported which comprise: frame-shift deletions or insertions (40\%), nonsense (20\%), missense (25\%), splice-site alterations (8\%), in-frame deletions or insertions (6\%), and large deletions (1\%) [Agarwal and Marx, unpubl., 7]. Thus, 70-75\% of the MEN1 gene mutations are inactivating causing premature protein truncation, while many mutations (such as rare missense in nonfamilial cases) can be classified as mutations of unknown clinical significance due to lack of available as-says that could provide evidence for an adverse physiological consequence of such mutations.

Identification of the genetic cause of the disease has become useful for the diagnosis of atrisk carriers affected by MEN1, and to rule out the disease in unaffected relatives of mutation-positive individuals. Although finding a pathologic $M E N 1$ gene mutation predicts the MEN1 syndrome, absence of mutation in a patient with MEN1 tumors does not exclude the possibility that the individual is affected with MEN1 [3].

Patients with incomplete MEN1 characteristics have been described as MEN1-like, where tumor occurs in as few as one of the three main MEN1-associated endocrine tissues [8]. In the $30 \%$ of MEN1 index cases without a germline MEN1 gene mutation or in those cases that are MEN1-like but without an identified MEN1 gene mutation, mutations could occur in regions not interrogated by typical screening methods, or mutations could occur in other genes. Candidate gene mutation analysis or whole genome/exome sequencing approaches could help identify the causative genes. The $p 27$ gene encoding one of the cyclin-dependent kinase inhibitors (CDKI) is one such candidate gene. Homozygous germline-inactivating mutation of the $p 27$ gene was found in a laboratory rat strain with a tumor spectrum similar to MEN1 and MEN2 with an additional feature of cataract (a syndrome named MENX) [for details about MEN2, see chapter by Lodish and for MENX, see chapter by Chou et al., this vol.]. Subsequently, the heterozygous germline p27 gene mutation has been reported in a few human MEN1-like cases. The CDKI genes consist of two families with total 7 members, the INK4 family ( $p 15, p 16, p 18$ and $p 19)$ and the Cip/Kip family ( $p 21, p 27$ and $p 57)$, that negatively regulate progression through the cell cycle by inhibiting specific cyclin-CDK complexes. Possible rare heterozygous germline mutations have been observed in four CDKI genes $(p 15, p 18, p 21$ and $p 27)$ in index cases with MEN1 or MEN1-like disease [9]. In the OMIM database, MEN syndrome with the $p 27$ gene mutation was named MEN4 [see chapter by Chou et al., this vol., for details about MEN4]. No obvious genotype/phenotype correlation has emerged from the analysis of the few CDKI gene mutations reported in MEN1 and MEN1-like index cases. Interestingly, a mouse model with combined knockout of the $p 18$ and $p 27$ genes has shown features similar to MEN1 and MEN2A underscoring 
the importance of finding rare germline mutations in CDKI genes in human MEN1 and related states [10].

\section{Mouse Models of MEN1}

To study the consequence of MEN1 gene loss, conventional and conditional knockout mouse models have been generated. Mice with germline homozygous loss of the Men1 gene (Men1-I-) die in utero between embryonic days 10.5 and 14.5 [11]. Approximately 30-40\% of the embryos show delayed development with craniofacial abnormalities, defective neural tube closure, heart hypertrophy, abnormal liver organization, hemorrhages, and edemas [11]. Mice with germline heterozygous loss of the Men1 gene (Men1+/-) have been generated in four different laboratories (in Australia, France, UK and USA). These mice gestate normally, but are tumor prone. After 9-16 months, they develop endocrine tumors similar to those in the human MEN1 syndrome: parathyroid tumors, pancreatic islet tumors (mainly insulinoma; also, glucagonoma, glucagon + insulin mixed-hormone tumors, or gastrinoma), anterior pituitary tumors (mainly prolactinoma; also, GH-secreting somatotropinoma), adrenal cortical tumors, thyroid tumors, gonadal tumors (Leydig cells in male, or ovarian stroma in female), mammary gland tumors, and lipomas [11]. Tumors in conventional Men1+/- mice exhibit loss of the wild-type Men1 allele (LOH), thus supporting a tumor suppressor role of the Men 1 gene in these tissues [11].

Conditional homozygous knockouts of the Men1 gene in various MEN1-associated target tissues in mice have been generated using floxed Men1 alleles and Cre-recombinase under the control of different tissue-specific promoters: parathyroid hormone promoter (PTH-Cre, for parathyroid cells), rat insulin promoter (Rip-Cre, for islet $\beta$-cells), glucagon promoter (GLU-Cre, for islet a-cells), and Pdx1 promoter (Pdx1-Cre for whole pancreas, exocrine and endocrine). After 9 months, mice with parathyroid-specific Men1 gene knockout develop parathyroid hyperplasia and hypercalcemia [11]. Pancreatic islet $\beta$-cell-specific Men1 gene knockout mice develop insulinomas (adenoma or carcinoma) at an earlier age (6 months) than the conventional Men1+/- mice [11]. Also, pancreatic a-cell-specific Men1 gene knockout mice after 12 months show mostly insulinomas rather than the expected glucagonomas - a phenotype attributed to trans-differentiation of a-cells into $\beta$-cells, or the possible involvement of paracrine signals that induce $\beta$-cell proliferation $[11,12]$. Despite loss of the Men 1 gene in the whole pancreas, Pdx1-Cre-driven Men 1 gene knockout mice develop tumors only in the endocrine pancreatic $\beta$-cells (insulinomas) after 10-12 months [11]. These observations highlight the importance of menin as a tumor suppressor in the parathyroid cells, and pancreatic $\beta$-cells. Although loss of menin expression occurs early in embryogenesis in the conditional knockout mice, delayed tumor formation implicates other hits for tumor formation.

Another mouse model with liver-specific homozygous Men1 gene knockout develops normally, and lacks tumors in the liver, suggesting that Men1 gene loss in the liver (a nonMEN1 target tissue) is tolerated and a tissue-specific action of menin is required for tumor suppression in MEN1-associated target tissues [11]. 
Some tumor types are specific to MEN1 in mouse, e.g. bilateral pheochromocytoma, and gonadal tumors are not observed in human MEN1 patients. Also, islet tumors in the conventional and conditional Men1 gene knockout mouse models begin with polyclonal hyperplasia, a precursor stage observed in mice but not in humans. Pancreatic tissue from these mice could serve as a unique approach to study tumor progression and to identify other possible hits after Men1 gene loss that play a role in tumorigenesis.

A MEN1 mouse model (germline Men1+/-) has been used to study the efficacy of antiangiogenesis treatment (anti-VEGF-A monoclonal antibody, mAb G6-31) [13]. This treatment inhibited pituitary tumor growth in situ and in transplants, and lowered the elevated serum prolactin level. Also, similar efficacy was observed against pancreatic islet tumors [13]. Hence, mouse models could serve as possible surrogates for studying MEN1 and related states.

\section{Menin-Null Cell Lines}

To gain molecular insights about MEN1, a critical resource is the availability of cell lines from the tumor types associated with the disease. Cell lines from human or mouse MEN1associated endocrine tissues with biallelic inactivation of the MEN1 gene have not yet been established. Menin-null mouse embryonic stem cells (ESCs) and menin-null immortalized mouse embryonic fibroblasts (MEFs) have been derived using embryos from the mouse models of MEN1 [14-16]. A menin-null Leydig cell tumor cell line (LCT10) has been derived from a male Men1+/- mouse with Leydig cell tumor (testicular interstitial cell tumor, a tumor type not found in human MEN1 cases) [17]. Reconstituted expression of menin in the menin-null MEFs or in the LCT10 cell line delays progression through the cell cycle and reduces their proliferation rate, in agreement with the tumor suppressor function of menin $[16,17]$. MEFs have been used extensively for the functional analysis of menin. Wild-type and menin-null ESCs have been used for in vitro differentiation into pancreatic islet-like endocrine cells to generate homogeneous populations of cells to serve as an alternative source of menin-null endocrine cells [18]. Such cells have been used for genomewide studies to compare wild-type and menin-null cells for gene expression changes and other assays [18]. Thus, mouse ESCs could be used for generating other MEN1associated endocrine cell types by in vitro differentiation protocols to aid in the analysis of endocrine-specific tumor suppressor functions of menin.

\section{Menin Expression and Function}

Menin is a ubiquitously expressed $67-\mathrm{kDa}$ predominantly nuclear protein highly conserved in animal species (with no known homologs in yeast and nematodes). Localization to the nucleus is mediated by the two nuclear localization signals (NLS), NLS1 (amino acid residues 479-497) and NLS2 (amino acid residues 588-608), and a third accessory NLS, NLSa (amino acid residues 546-572) [7]. Most of the nonsense and frame-shift mutations in the MEN1 gene predict premature protein truncation and thus loss of NLS, preventing the normal localization of menin in the nucleus. 
Menin is reported to undergo phosphorylation at 6 different amino acid residues - Ser394, Thr397, Thr399, Ser487, Ser543, and Ser583 - constitutively (Ser543), or in response to DNA damage (Ser394 and Ser487) or upon loss of phosphorylation at Ser394 (Thr397 and Thr399) [19]. The importance of menin phosphorylation in tumorigenesis remains to be determined.

The primary amino acid sequence of menin is conserved but does not show any obvious homologous domains or motifs that would allow prediction about its biological function. Menin has not been shown to possess any enzymatic activity. Therefore, to uncover the physiologic processes perturbed upon loss of menin that lead to tumor formation, many proteins that interact directly or form a complex with menin have been identified. Work from many laboratories, using various protein/protein interaction methods, has reported approximately 40 different proteins that could partner with menin implicating a role for menin in the pathways and processes regulated by these interacting partners (table 2). Menin partners include DNA-binding transcription factors, chromatin modifying proteins and complexes, transcription initiation or elongation proteins, DNA-repair proteins associated with response to DNA damage, a protein responsible for mutant-protein degradation, signaling mediators in the cytoplasm, and cytoplasmic proteins associated with the cytoskeleton, cell division, adhesion or motility. Through interaction with transcription factors or chromatin-modifying protein complexes, menin acts as a transcriptional regulator either as a repressor or activator of transcription. This chapter will focus on some aspects of the interaction of menin with the transcription factor JUND, and with the chromatinmodifying mixed lineage leukemia (MLL) complex. Readers may refer to other articles and reviews that cover more protein partners mentioned in table 2 .

\section{Menin Interaction with JUND}

A conventional yeast two-hybrid library screening with menin identified JUND as a menininteracting partner in two different laboratories [20, 21]. Menin interacts directly with JUND, a member of the activator protein-1 (AP1) transcription factor family that consists of JUN (JUNB, c-JUN, and JUND) and FOS (c-FOS, FRA-1 and FRA-2) proteins [20, 21]. JUN and FOS are cellular homologs of viral oncogenes that bind to specific DNA sequences, the TPA-responsive element (TRE), to activate transcription. The activity of the AP1 complex consisting of JUN/JUN homodimers or JUN/FOS heterodimers has been linked to cancer and neoplastic transformation. However, no mutations in the JUN or FOS genes have been identified so far. Through their target genes, AP1 proteins have been reported to regulate processes such as cell proliferation, differentiation, apoptosis, angiogenesis, cell motility and invasiveness.

Menin specifically interacts with JUND in multiple protein/protein interaction assays, and does not interact directly with other AP1 family members [20, 21]. In reporter assays, menin represses transcription activated by JUND [20,21]. Although menin does not interact physically with c-JUN, in reporter assays menin enhances transcription activated by c-JUN [20]. The transcriptional activation domains of the JUN transcription factors are located at their $\mathrm{N}$-terminus and the DNA binding and dimerization region (bZIP domain) is located at their C-terminus. The menin-interacting region is located at the N-terminus of JUND [20, 
21]. Synthetic mutations in JUND that disrupt menin interaction have been isolated by reverse yeast two-hybrid screening, which mapped the menin-interacting region in JUND to the PGAP motif (corresponding to amino acid residues 33-36 in human JUND, or 41-44 in mouse JunD) [22]. JUND can suppress growth of normal MEFs; however, JUND is unable to suppress growth of menin-null MEFs [23]. Furthermore, experiments conducted in JUND-null MEFs have shown that a JUND mutant that lacks menin-binding (mouse JUNDG42E, corresponding to human JUND amino acid residue G34) converts the growthsuppressing JUND into a growth-promoting factor [23]. JUND-null MEFs stably expressing this menin-interaction-deficient JUND mutant form tumors in nude mice highlighting the oncogenic property of this mutant [Agarwal and Marx, unpubl.]. Disease-associated missense mutations in menin located at amino acid residues 139-242 impair binding to JUND [20]. These observations strongly suggest that the menin/JUND partnering plays an important role in tumor suppression. Target genes and pathways regulated by this partnering of menin remain to be determined.

In contrast to mice with homozygous knockout of $c$-Jun and JunB genes, inactivation of the $J u n D$ gene in mice does not lead to embryonic lethality perhaps due to genetic redundancy from the other members of the AP1 family as shown by knockin mouse models where JunB and JunD could substitute for c-Jun in embryonic development [24]. Homozygous JunD gene knockout mice although viable and healthy, exhibit: postnatal growth retardation, agedependent defective spermatogenesis, enhanced cardiomyocyte apoptosis and fibrosis, chronic kidney disease, and increased bone formation [24, 25]. Transgenic mice broadly expressing JunD (controlled by the ubiquitin promoter) are viable and normal, but show reduced proliferation of lymphoid cells [26]. Whether these phenotypes, or the phenotypes described above in the mouse models of MEN1, are modified upon loss or gain of menin/JUN partnering is not known.

Genetic studies in the fruit fly, Drosophila, support the function of menin to modulate JUN activity. The Drosophila melanogaster menin (Mnn1) shows $47 \%$ amino acid identity with human menin. Unlike the early embryonic lethality of the Men1-/- mice described above, homozygous mnn1-null flies are viable and fertile [27]. Interestingly, flies with localized overexpression of Mnn1 show defects in thoracic closure (cleft thorax), a phenotype similar to insufficient activity of DJun (only a single Jun gene is present in Drosophila, i.e. the DJun gene) [27]. Mnn1 does not interact with DJun in biochemical assays; however, genetic experiments in flies have shown that overexpression of Mnn1 in a heterozygous DJun background or together with over-expression of a dominant negative DJun caused a more severe thoracic cleft phenotype [27]. These observations indicate that this complex interaction of menin with JUN proteins is evolutionarily conserved, and important for normal development.

\section{Menin Interaction with the MLL Complex}

Menin is an integral component of two similar MLL complexes, containing either MLL1 or MLL2. Mass spectrophotometric analysis of anti-menin immunoprecipitates of HeLa or HEK293T cells identified a protein complex containing RPB2 (large subunit of RNA Pol II), MLL2, Menin, ASH2L, RBBP5, WDR5, and hDPY30 [28]. Mass spectrophotometric 
analysis of anti-MLL1 immunoprecipitates of K562 erythroleukemia cells identified a protein complex containing MLL1 $\left(\mathrm{MLL}^{\mathrm{N}}\right.$ and $\left.\mathrm{MLL}^{\mathrm{C}}\right)$, HCF-2, Menin, ASH2L1, ASH2, RBBP5 and WDR5 [29].

These menin-MLL complexes have an enzymatic activity (histone methyltransferase, HMTase) catalyzing a specific covalent histone modification, trimethylated histone $\mathrm{H} 3$ on lysine 4 (H3K4me3) [28, 29]. H3K4me3 is associated with activation of gene transcription. In these complexes, menin interacts directly with MLL, the human homolog of Drosophila trithorax [30]. Several disease-associated menin missense mutants are impaired for MLL interaction, and highly reduced HMTase activity is observed in anti-menin immunoprecipitates from cells expressing the same menin missense mutants [28]. These findings highlight the functional significance of menin/MLL partnering showing that H3K4me3 would be lost on specific genes in the absence of menin resulting in repression of gene transcription.

The importance of the menin/MLL partnering and menin-dependent H3K4me3 in MEN1associated tumorigenesis has been studied in a mouse model with tissue-specific combined loss of menin and the $\mathrm{H} 3 \mathrm{~K} 4 \mathrm{me} 2 / \mathrm{H} 3 \mathrm{~K} 4 \mathrm{me} 3$ demethylase Rbp2 in pancreatic $\beta$-cells [31]. Loss of Rbp2 H3K4 demethylase activity would allow $\mathrm{H} 3 \mathrm{~K} 4 \mathrm{me} 3$ on specific genes even in the absence of menin-MLL complex activity, and rescue tumor formation driven by menin loss. Rbp2 gene loss substantially decreased tumor burden and enhanced median survival age from 45 weeks (Men1 gene knockout in $\beta$-cells) to 69 weeks (combined knockout of Men1 and Rbp2 genes in $\beta$-cells) [31]. This rescue of tumorigenesis from inhibition of RBP2 (and its histone demethylase activity) reveals RBP2 as a potential cancer therapeutic target for further studies.

Translocations involving the MLL gene are a common cause of acute lymphoid and myeloid leukemias (the so-called mixed lineage leukemia). During normal hematopoiesis, MLL regulates the expression of specific $H O X$ genes. Leukemic MLL translocations upregulate the expression of HOXA7, HOXA9 or the HOX cofactor MEIS1, which block hematopoietic differentiation thereby promoting leukemogenesis [29]. Furthermore, menin serves as an adaptor to link MLL with LEDGF (lens epithelium-derived growth factor), another chromatin-associated protein, on specific $H O X$ genes [30]. Some menin missense mutants show impaired LEDGF interaction, while retaining interaction with MLL, but they are deficient in MLL/menin-associated HMTase activity [30]. Work done in different laboratories has shown that interaction with menin is critical for the oncogenic function of MLL fusion proteins. In contrast to its tumor suppressor function in MEN1, menin acts as an oncogenic co-factor of MLL in leukemia.

Studies exploring the association of menin in the chromatin-modifying MLL-complex have led to the identification of $\mathrm{H} 3 \mathrm{~K} 4 \mathrm{me} 3$-dependent menin-regulated genes such as the $\mathrm{HOX}$ genes, the CDKI genes $p 18$ and $p 27$, and genes at the imprinted MEG3 locus [18, 32-34]. The $H O X$ gene family consists of 39 genes located in 4 clusters on different chromosomes. They are highly conserved transcription factors that regulate the development of the embryonic body plan during embryogenesis. Dysregulated expression of $H O X$ genes has been noted in leukemia and in solid tumors including in sporadic and MEN1-associated 
parathyroid tumors [35]. Reduced expression of CDKI genes $p 18$ and $p 27$ that negatively regulate progression through the cell cycle has been observed in islet tumors from the mouse models of MEN1 [32]. The MEG3 locus contains co-ordinately regulated imprinted genes, and downregulation of these genes have been observed in sporadic pituitary tumors [36]. These investigations have provided valuable insights into the functional role of the menin/ MILL complex partnering.

\section{D Crystal Structure of Menin}

For many years, efforts to decipher the crystal structure of menin were unsuccessful in several laboratories perhaps due to disordered internal fragments that could hinder protein crystallization. After the deletion of such unstructured regions, two different laboratories (both from the University of Michigan) have since successfully obtained menin crystals [37, 38]. They determined the crystal structure of Nematostella menin (the starlet sea anemone) and human menin using X-ray diffraction at resolutions of 1.95 and $2.5 \AA$, respectively. Based on the prediction of disordered regions, deletion of an unstructured loop (amino acid residues 426-442) and truncation of the C-terminus (amino acid residues 487-539) in Nematostella menin and deletion of a single internal unstructured loop (amino acid residues 460-519) in human menin yielded protein that crystallized easily [37, 38]. The structures of human and Nematostella menin are very similar (PBD ID: human, 3U84; Nematostella, 3RE2). The 3D shape of menin is described as a curved left 'hand' with a pocket formed by its 'thumb' and 'palm'. The basic structure reveals four domains in menin: an N-terminal domain consisting of a long $\beta$-hairpin, a transglutaminase-like domain that forms the 'thumb', a helical 'palm' domain of eight a helices that contain three tetratricopeptide (TRP) motifs, and a carboxy-terminal 'fingers' domain that has no homology with any known motifs [37, 38]. The transglutaminase-like domain in menin is predicted to lack enzymatic activity [37, 38]. Given the number of proteins that have been reported to partner with menin, the presence of TRP motifs is of interest because TRP is a structural motif known to serve as a scaffold for protein-protein interactions and the assembly of multiprotein complexes [37, 38]. Although menin participates in transcriptional regulation, no DNA-binding interface has been located in the 3D structure of menin to indicate direct binding of menin to DNA.

Disease-related mutations, missense $(n=60)$ and in-frame deletions $(n=10)$ are localized in all the different domains in the 3D structure of menin, changing buried residues, thus predicting destabilization of the menin structure and loss of protein function [37, 38]. Several menin missense mutant proteins have been shown to express poorly in cells because they are targeted to the proteasome and rapidly degraded [39]. Mapping of MEN1 gene mutations to the menin structure could be informative for exploring the consequence of mutations of unknown clinical significance, and to distinguish pathologic and benign mutations.

The crystal structure of human menin individually with its partners JUND or MLL1, or together with MLL1 and LEDGF reveal that binding of JUND and MLL1 to menin is mutually exclusive [38]. These structures show that menin contains a deep pocket (in the 'palm' domain) that binds short peptides of JUND (amino acid residues 27-47) or MLL1

Front Horm Res. Author manuscript; available in PMC 2018 December 05. 
(amino acid residues 6-25) [38]. In the menin-MLL1-LEDGF complex, menin could bind to MLL1 through the peptide pocket while LEDGF was located at a distinct surface formed by the interaction of menin and MLL1 [38]. Structural features of menin with other partners remain to be determined.

\section{Conclusions}

Clinical, genetic and basic findings about MEN1, the MEN1 gene and menin have advanced the understanding of this disease. Identification of a germline MEN1 gene mutation in atrisk individuals allows early monitoring for tumors. Mouse models and protein interaction studies have helped explore the critical biological function(s) of menin. These studies have revealed candidate protein partners and men independent target genes that should be studied further to understand the exact mechanisms of action of menin in normal physiology and actions potentially perturbed during tumor formation. The 3D crystal structure of menin will facilitate such investigations. Applications of this knowledge will help develop new diagnostic methods and treatment options for MEN1 and related states, and for similar sporadic tumors.

\section{Acknowledgments}

This work was supported by the Intramural Research Program of the NIH, National Institute of Diabetes and Digestive and Kidney Diseases (Project No. 1ZIADK075035-03).

\section{References}

1. Moldawer MP, Nardi GL, Raker JW: Concomitance of multiple adenomas of the parathyroids and pancreatic islets with tumor of the pituitary: a syndrome with a familial incidence. Am J Med Sci 1954;228:190-206. [PubMed: 13180511]

2. Wermer P: Genetic aspects of adenomatosis of endocrine glands. Am J Med 1954;16:363-371. [PubMed: 13138607]

3. Brandi ML, Gagel RF, Angeli A, et al.: Guidelines for diagnosis and therapy of MEN type 1 and type 2. J Clin Endocrinol Metab 2001;86:5658-5671. [PubMed: 11739416]

4. Larsson C, Skogseid B, Oberg K, Nakamura Y, Nordenskjold M: Multiple endocrine neoplasia type 1 gene maps to chromosome 11 and is lost in insulinoma. Nature 1988;332:85-87. [PubMed: 2894610]

5. Chandrasekharappa SC, Guru SC, Manickam P, et al.: Positional cloning of the gene for multiple endocrine neoplasia-type 1. Science 1997;276:404-407. [PubMed: 9103196]

6. Lemmens I, Van de Ven WJ, Kas K, et al.: Identification of the multiple endocrine neoplasia type 1 (MEN1) gene. The European consortium on MEN1. Hum Mol Genet 1997;6:1177-1183. [PubMed: 9215690]

7. Thakker RV: Multiple endocrine neoplasia type 1 (MEN1). Best Pract Res Clin Endocrinol Metab 2010;24:355-370. [PubMed: 20833329]

8. Agarwal SK, Ozawa A, Mateo CM, Marx SJ: The MEN1 gene and pituitary tumours. Horm Res 2009;71 (suppl 2):131-138. [PubMed: 19407509]

9. Agarwal SK, Mateo CM, Marx SJ: Rare germline mutations in cyclin-dependent kinase inhibitor genes in multiple endocrine neoplasia type 1 and related states. J Clin Endocrinol Metab 2009;94: 1826-1834. [PubMed: 19141585]

10. Franklin DS, Godfrey VL, Lee H, Kovalev GI, Schoonhoven R, Chen-Kiang S, Su L, Xiong Y: CDK inhibitors p18(Ink4c) and p27(Kip1) mediate two separate pathways to collaboratively suppress pituitary tumorigenesis. Genes Dev 1998;12:2899-2911. [PubMed: 9744866] 
11. Piret SE, Thakker RV: Mouse models for inherited endocrine and metabolic disorders. J Endocrinol 2011;211:211-230. [PubMed: 21765099]

12. Lu J, Herrera PL, Carreira C, Bonnavion R, Seigne C, Calender A, Bertolino P, Zhang CX: Alpha cell-specific MEN1 ablation triggers the transdifferentiation of glucagon-expressing cells and insulinoma development. Gastroenterology 2010;138: 1954-1965. [PubMed: 20138042]

13. Korsisaari N, Ross J, Wu X, Kowanetz M, Pal N, Hall L, Eastham-Anderson J, Forrest WF, Van Bruggen N, Peale FV, Ferrara N: Blocking vascular endothelial growth factor-a inhibits the growth of pituitary adenomas and lowers serum prolactin level in a mouse model of multiple endocrine neoplasia type 1. Clin Cancer Res 2008;14: 249-258. [PubMed: 18172277]

14. Novotny E, Compton S, Liu PP, Collins FS, Chandrasekharappa SC: In vitro hematopoietic differentiation of mouse embryonic stem cells requires the tumor suppressor menin and is mediated by Hoxa9. Mech Dev 2009;126:517-522. [PubMed: 19393316]

15. Ji Y, Prasad NB, Novotny EA, Kaur S, Elkahloun A, Chen Y, Zhang RZ, Chu ML, Agarwal SK, Marx SJ, Collins FS, Chandrasekharappa SC: Mouse embryo fibroblasts lacking the tumor suppressor menin show altered expression of extracellular matrix protein genes. Mol Cancer Res 2007;5:1041-1051. [PubMed: 17951404]

16. Schnepp RW, Mao H, Sykes SM, Zong WX, Silva A, La P, Hua X: Menin induces apoptosis in murine embryonic fibroblasts. J Biol Chem 2004;279: 10685-10691. [PubMed: 14688275]

17. Hussein N, Casse H, Fontaniere S, Morera AM, Asensio MJ, Bakeli S, Lu JL, Coste I, Di Clemente $\mathrm{N}$, Bertolino P, Zhang CX: Reconstituted expression of menin in MEN1-deficient mouse Leydig tumour cells induces cell cycle arrest and apoptosis. Eur J Cancer 2007;43:402-414. [PubMed: 17184987]

18. Agarwal SK, Jothi R: Genome-wide characterization of menin-dependent h3k4me3 reveals a specific role for menin in the regulation of genes implicated in MEN1-like tumors. PLoS One 2012; 7:e37952. [PubMed: 22666422]

19. Francis J, Lin W, Rozenblatt-Rosen O, Meyerson M: The menin tumor suppressor protein is phosphorylated in response to DNA damage. PLoS One 2011; 6:e16119. [PubMed: 21264250]

20. Agarwal SK, Guru SC, Heppner C, Erdos MR, Collins RM, Park SY, Saggar S,

Chandrasekharappa SC, Collins FS, Spiegel AM, Marx SJ, Burns AL: Menin interacts with the AP1 transcription factor JUND and represses JUND-activated transcription. Cell 1999;96:143152. [PubMed: 9989505]

21. Gobl AE, Berg M, Lopez-Egido JR, Oberg K, Skogseid B, Westin G: Menin represses JUNDactivated transcription by a histone deacetylase-dependent mechanism. Biochim Biophys Acta 1999;1447:51-56. [PubMed: 10500243]

22. Knapp JI, Heppner C, Hickman AB, Burns AL, Chandrasekharappa SC, Collins FS, Marx SJ, Spiegel AM, Agarwal SK: Identification and characterization of JUND missense mutants that lack menin binding. Oncogene 2000;19:4706-4712. [PubMed: 11032020]

23. Agarwal SK, Novotny EA, Crabtree JS, Weitzman JB, Yaniv M, Burns AL, Chandrasekharappa SC, Collins FS, Spiegel AM, Marx SJ: Transcription factor JUND, deprived of menin, switches from growth suppressor to growth promoter. Proc Natl Acad Sci USA 2003;100:10770-10775. [PubMed: 12960363]

24. Meixner A, Karreth F, Kenner L, Penninger JM, Wagner EF: JUN and JUND-dependent functions in cell proliferation and stress response. Cell Death Differ 2010;17:1409-1419. [PubMed: 20300111]

25. Thepot D, Weitzman JB, Barra J, Segretain D, Stinnakre MG, Babinet C, Yaniv M: Targeted disruption of the murine JUND gene results in multiple defects in male reproductive function. Development 2000;127:143-153. [PubMed: 10654608]

26. Meixner A, Karreth F, Kenner L, Wagner EF: JUND regulates lymphocyte proliferation and T helper cell cytokine expression. Embo J 2004;23:1325-1335. [PubMed: 15029240]

27. Cerrato A, Parisi M, Santa Anna S, Missirlis F, Guru S, Agarwal S, Sturgill D, Talbot T, Spiegel A, Collins F, Chandrasekharappa S, Marx S, Oliver B: Genetic interactions between Drosophila melanogaster menin and Jun/Fos. Dev Biol 2006;298:59-70. [PubMed: 16930585]

28. Hughes CM, Rozenblatt-Rosen O, Milne TA, Copeland TD, Levine SS, Lee JC, Hayes DN, Shanmugam KS, Bhattacharjee A, Biondi CA, Kay GF, Hayward NK, Hess JL, Meyerson M: 
Menin associates with a trithorax family histone methyltransferase complex and with the hoxc8 locus. Mol Cell 2004;13: 587-597. [PubMed: 14992727]

29. Yokoyama A, Wang Z, Wysocka J, Sanyal M, Aufiero DJ, Kitabayashi I, Herr W, Cleary ML: Leukemia proto-oncoprotein MLL forms a SET1-like his-tone methyltransferase complex with menin to regulate Hox gene expression. Mol Cell Biol 2004; 24:5639-5649. [PubMed: 15199122]

30. Yokoyama A, Cleary ML: Menin critically links MLL proteins with LEDGF on cancer-associated target genes. Cancer Cell 2008;14:36-46. [PubMed: 18598942]

31. Lin W, Cao J, Liu J, et al.: Loss of the retinoblastoma binding protein 2 (RBP2) histone demethylase suppresses tumorigenesis in mice lacking RB1 or MEN1. Proc Natl Acad Sci USA 2011;108:13379-13386. [PubMed: 21788502]

32. Karnik SK, Hughes CM, Gu X, Rozenblatt-Rosen O, McLean GW, Xiong Y, Meyerson M, Kim SK: Menin regulates pancreatic islet growth by promoting histone methylation and expression of genes encoding p27Kip1 and p18INK4c. Proc Natl Acad Sci USA 2005;102:14659-14664. [PubMed: 16195383]

33. Scacheri PC, Davis S, Odom DT, Crawford GE, Perkins S, Halawi MJ, Agarwal SK, Marx SJ, Spiegel AM, Meltzer PS, Collins FS: Genome-wide analysis of menin binding provides insights into MEN1 tumorigenesis. PLoS Genet 2006;2:e51. [PubMed: 16604156]

34. Wang P, Lin C, Smith ER, Guo H, Sanderson BW, Wu M, Gogol M, Alexander T, Seidel C, Wiedemann LM, Ge K, Krumlauf R, Shilatifard A: Global analysis of H3K4 methylation defines MLL family member targets and points to a role for MLL1-mediated H3K4 methylation in the regulation of transcriptional initiation by RNA polymerase II. Mol Cell Biol 2009;29:6074-6085. [PubMed: 19703992]

35. Shen HC, Rosen JE, Yang LM, Savage SA, Burns AL, Mateo CM, Agarwal SK, Chandrasekharappa SC, Spiegel AM, Collins FS, Marx SJ, Libutti SK: Parathyroid tumor development involves deregulation of homeobox genes. Endocr Relat Cancer 2008;15: 267-275. [PubMed: 18310293]

36. Zhou Y, Zhang X, Klibanski A: MEG3 noncoding RNA: a tumor suppressor. J Mol Endocrinol 2012; 48:R45-R53. [PubMed: 22393162]

37. Murai MJ, Chruszcz M, Reddy G, Grembecka J, Cierpicki T: Crystal structure of menin reveals binding site for mixed lineage leukemia (MLL) protein. J Biol Chem 2011;286:31742-31748. [PubMed: 21757704]

38. Huang J, Gurung B, Wan B, Matkar S, Veniaminova NA, Wan K, Merchant JL, Hua X, Lei M: The same pocket in menin binds both MLL and JUND but has opposite effects on transcription. Nature 2012;482: 542-546. [PubMed: 22327296]

39. Canaff L, Vanbellinghen JF, Kanazawa I, Kwak H, Garfield N, Vautour L, Hendy GN: Menin missense mutants encoded by the MEN1 gene that are targeted to the proteasome: restoration of expression and activity by chip SIRNA. J Clin Endocrinol Metab 2012;97:E282-E291. [PubMed: 22090276] 
Table 1.

Tumors associated with the MEN1 syndrome

\begin{tabular}{|c|c|}
\hline Tumors & $\%$ penetrance (at age 40 ) \\
\hline \multicolumn{2}{|l|}{ Endocrine (hormone-secreting or NF) } \\
\hline Parathyroid & 90 \\
\hline \multicolumn{2}{|l|}{ Entero-pancreatic neuroendocrine } \\
\hline Gastrinoma $^{*}$ & 40 \\
\hline Insulinoma & 10 \\
\hline $\mathrm{NF}^{*}$, PPoma ${ }^{*}$ & 20 \\
\hline Glucagonoma ${ }^{*}$, VIPoma ${ }^{*}$, Somatostatinoma ${ }^{*}$, etc. & 2 \\
\hline \multicolumn{2}{|l|}{ Anterior pituitary } \\
\hline Prolactinoma & 20 \\
\hline $\mathrm{GH}+$ prolactin secreting & 5 \\
\hline GH secreting & 5 \\
\hline NF & 5 \\
\hline ACTH-secreting & 2 \\
\hline \multicolumn{2}{|l|}{ Adrenal } \\
\hline Cortex NF & 25 \\
\hline Medulla & 1 \\
\hline \multicolumn{2}{|l|}{ Foregut carcinoid } \\
\hline Gastric ECLoma NF & 10 \\
\hline Thymic carcinoid ${ }^{*} \mathrm{NF}$ & 4 \\
\hline Bronchial carcinoid ${ }^{*} \mathrm{NF}$ & 2 \\
\hline \multicolumn{2}{|l|}{ Nonendocrine } \\
\hline Facial angiofibroma & 85 \\
\hline Truncal collagenoma & 70 \\
\hline Lipoma & 30 \\
\hline Meningioma & 5 \\
\hline Barrett's esophagus & 5 \\
\hline \multicolumn{2}{|l|}{ Leiomyoma } \\
\hline Uterus (in female) & 30 \\
\hline Esophagus & 5 \\
\hline Ependymoma & 1 \\
\hline
\end{tabular}

$\mathrm{NF}=$ Nonfunctioning; $\mathrm{GH}=$ growth hormone; PPoma = tumor secreting pancreatic polypeptide; VIPoma = tumor secreting vasoactive intestinal polypeptide; ECLoma = tumor of enterochromaffin-like cells; ACTH = adrenocorticotropic hormone.

Tumor type with malignant potential for $25 \%$ or more cases.

Modified from Agarwal et al. [18]. 
Table 2.

Proteins reported to partner with menin

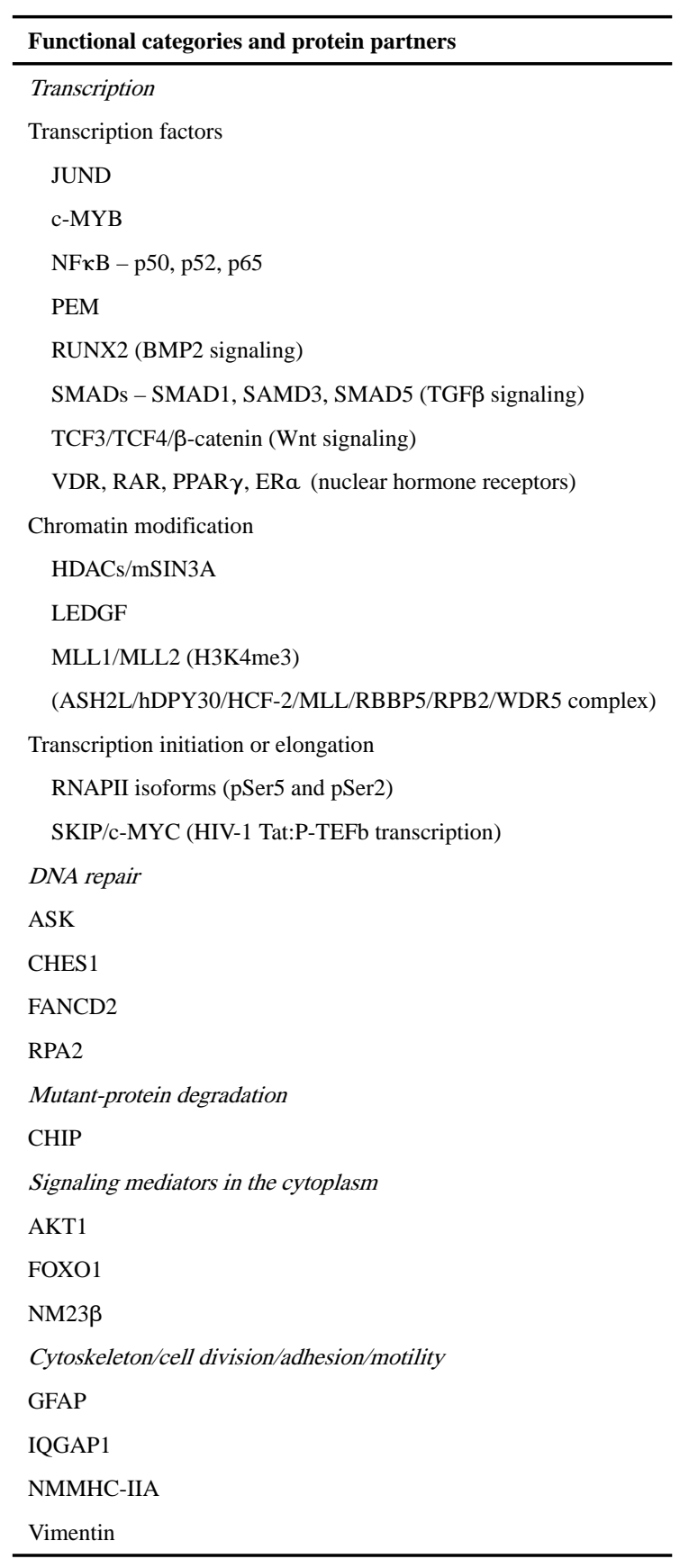

